\title{
SEISMIC VULNERABILITY ANALYSIS IN URBAN SYSTEMS AND ROAD NETWORKS. APPLICATION TO THE CITY OF THESSALONIKI, GREECE
}

\author{
A.J. ANASTASSIADIS ${ }^{1} \&$ S.A. ARGYROUDIS ${ }^{2}$ \\ ${ }^{1}$ Department of Architecture, Aristotle University of Thessaloniki, Greece. \\ ${ }^{2}$ Department of Civil Engineering, Aristotle University of Thessaloniki, Greece.
}

\begin{abstract}
During the last decades, the aggregation of human, financial and environmental losses related to natural disasters has been increased, constituting a principal threat for the function of modern society. The present paper proposes an integrated methodology for the seismic risk management in urban areas, focused on urban planning and sustainable development. In this framework, the key elements for the urban vulnerability analysis during the crisis, restoration and especially pre-earthquake period are given. A method for the seismic risk analysis of urban roads is also described as the transportation network is of vital importance in case of emergency. The procedure is illustrated through a pilot application to the center of Thessaloniki city, which is an area that concentrates a variety of activities and is characterized by high seismicity. The urban vulnerability is estimated based on a value analysis of the exposed elements at risk, while the functionality of roads is evaluated after the estimation of indirect closures due to possible collapses of adjacent buildings.

Keywords: earthquake, risk management, road network, seismic risk, urban system, vulnerability.
\end{abstract}

\section{INTRODUCTION}

The earthquake constitutes an emergency situation with often devastating consequences on human life, living conditions, economic and cultural activities as well on the built environment. Greece lies in a region of high seismic activity, characterized by a significant frequency of catastrophic earthquakes in larger and smaller urban centers and tourist resorts. An efficient risk management requires an appropriate operational plan, based on a multilevel approach that takes into consideration the distinctive features of the urban space components - material and immaterial - exposed to seismic risk. The overall built environment, including the historical heritage and tradition of the country, is a multilevel system whose component parts, each one individually, play a specific role with their own significance in the event of a catastrophic earthquake. Especially the transportation and utility networks, the so-called lifelines, have a key role in sustaining life and growth of a community. The function of urban road network becomes more essential during crisis periods such as after a strong earthquake as it supports the emergency services.

The modern city is a dynamic system consisting of heterogeneous components. Throughout the previous century, the extensive development of cities has transformed their spatial planning features and led to a violent downgrading of the environment, to the extent that some of these cities are currently characterized by high vulnerability in the event of a catastrophic phenomenon. The question that must be addressed is 'how the urban system can be protected against such unpredictable phenomena'. In the following, the general principles of seismic risk management and urban vulnerability are presented through a methodology of the exposed elements' value analysis. Furthermore, the approach of urban vulnerability assessment is focused in the road network that directly interacts with the city's function. A pilot application of the proposed methodology for a central part of Thessaloniki city is described. A part of the analysis data is based on previous studies [1], where the authors participated. 


\section{CATASTROPHIC EVENTS AND RISK MANAGEMENT}

The difference between an emergency situation and a catastrophic one is that the former expresses the overall reaction of the city towards seismic events and usually precedes the latter, which in fact is the occurrence of the event. The catastrophe, therefore, lies closer to the event itself, than its consequences. This different approach indicates that we focus our attention on the internal mechanisms of a cataclysmic event. Accordingly, a series of models can be developed, which will combine and make use of elements of different disciplines including geotechnical earthquake engineering, structural engineering, seismology and urban planning (Cusp Catastrophe Models based on chaos and emergence theory, adapted to the particularities of urban space [2]).

The co-relation between risk reduction in the event of catastrophic phenomena and urban and spatial planning-design is obvious. If the latter is systematic, as described above, in a spirit of 'non-vulnerable growth', the all too frequent situation whereby natural catastrophes are viewed as temporary disruptions of the spatial system could be avoided [3]. The management of built space in the event of natural disasters as well as prevention and protection measures from such devastating phenomena are included in the overall urban planning framework and process. It is a specialized urban approach in the context of sustainable development. In order for it to be feasible and effective, measures taken must consider all limitations dictated by the space examined, as well as the parameters of economic and social evolution. The strongest indication of the importance of laying out such a risk management policy is the economic evaluation of the catastrophe.

Spatial and urban planning in the creation of such models implements zoning methods (zones of different risk level and potential) on the basis of the experience of catastrophic phenomena, making use of probability theory, according to the latent or experienced tendencies of urban areas to attract cataclysmic phenomena. The trends and the events differ from one country to the next, from one neighborhood to the other; they vary according to geological, climatic, urban planning, technological, political, social, economic, and administrative conditions [4].

\subsection{Urban vulnerability analysis. Spatial elements at risk}

There are two broad vulnerability approaches: the analytic approach and a more synthetic one founded on the principle of resilience to natural phenomena. In determining the extent to which the system is capable of overcoming the crisis and recovering, the concept of 'resilience' is recruited, a term essentially reminiscent of Physics (rupture point), but also of a series of other disciplines like ecology, economy, psychology, etc. When the social system has 'good resilience', its vulnerability is low and the recovery to its initial state is faster. Estimating resilience is a complicated process demanding a thorough knowledge of factors related to the dynamics and characteristics of the catastrophic phenomenon.

The parameters and components that must be taken into account are the natural phenomena processes, the degree of exposure of individuals and objects to the natural phenomena, prevention and readiness in the face of the crisis. The scope of each factor varies according to the risk type and fluctuates in relation to a series of socioeconomic, urban planning, spatial planning, and demographic parameters. Crisis only takes place when the aforementioned parameters are in interaction [5]. The determination of the different vulnerability-resilience levels of a population in the face of catastrophic phenomena could be more accurate if the available data were more sufficient. In the majority of cases of natural disasters it is common for the residents to be initially treated as casualties rather than individuals exposed to risk related to social processes. On the basis of risk management insufficiency, one could distinguish 'risk exposed communities' and 'vulnerable countries' [6]. 
What is, therefore, required is a comprehensive knowledge of the relations between catastrophes and risk management-planning. There are different approaches to analyze urban vulnerability, those that are quantitative in nature and aim at the evaluation of different prevention policies on a costbenefit basis and those that are qualitative and seek to identify the actual causes and the vulnerability parameters [7]. The analysis is usually performed for seismic risk scenarios of different earthquake levels, as for example a deterministic scenario (based on the occurrence of an earthquake of specified size at a specified location) and a probabilistic scenario (based on a combination of uncertainties in the size, location, and rate of recurrence of earthquakes).

\subsection{Spatial elements at risk}

In relation to risk management, the planning system is subdivided into the following categories: The natural, social, economic and the political environment. The five components that compose each of these categories are: population, space, spatial activities and functions, regulations and principles of governance, spatial representation and image. The analysis of the city's vulnerability lies in the identification, on the one hand, of fragility components - population, built environment, spatial organization, functions - and on the other, the reactions that are likely to aggravate this inherent fragility such as inappropriate development policies.

By 'vulnerable spatial elements' we refer to those elements corresponding to the human element of space, the objects it includes, the equipment and in general the elements of space that can be threatened by natural catastrophes and are susceptible to damage or injury. The first phase in the risk management planning involves the analysis of spatial elements at risk [8], listed below:

- The population in the wider sense, the human element, that is the permanent population (residents and people who work in the city) as well as the temporary one (people who work but do not live in the city - professional visitors, tourists, etc.).

- The residences, buildings and infrastructures of the city frequently receiving large numbers of visitors, such as public buildings, services, buildings housing central functions.

- Buildings of strategic significance characterized by their usefulness in crisis periods, such as hospitals, fire and police stations, communications centers, general infrastructure and basic decisionmaking centers (ministries, city hall, etc.), organizations.

- Monuments, buildings that belong to the cultural heritage of the city, buildings of architectural significance.

- Transportation networks (roadway, railway, underground, airport, port) with their subcomponents (bridges, tunnels, streets, terminal stations, etc.).

- Utility networks (electricity supply, telecommunications, water supply, natural gas, sewage disposal) with their subcomponents (substations, tanks, pipelines, etc.).

- Natural resources (forests, etc.).

- Special facilities such as nuclear power plants, toxic substance storage facilities.

- Landmarks of the city and natural symbols.

- Parameters of urban administration and crisis management and strategy. State officials, administrative, political and economic factors, various other decision-making bodies (organizations, universities, research centers), public health and crisis management specialists, institutions and socioeconomic factors, etc.

Furthermore, a risk management analysis also includes a population distribution study, an analysis of its socioeconomic characteristics and structure, functions of the city, productive and economic 
activities taking place within it, systems of its substructure and its superstructure as well as its relation to the wider region (Fig. 1).

\subsection{Seismic risk analysis of road network}

Recent major earthquakes all over the world have resulted in roadway system malfunctions that had both short- and long-term effects in the activities of the disaster area. The damages are distinguished to direct damage such as bridge and road, due to ground shaking or ground failure, and indirect such as street blockades, due to debris of collapsed buildings. Recently, various methodologies have been proposed for the seismic risk assessment of roadway and other lifelines, aiming to minimize losses and improve the pre-earthquake mitigation policy and post-earthquake restoration plans [9], while the development of GIS technologies offers valuable tools for the implementation of innovative and interactive techniques. The vulnerability of transportation system components are usually evaluated in terms of fragility functions, which are based on data from past earthquakes $[10,11]$, theoretical analyses $[10,12]$ or expert judgment [13]. The basic idea of the fragility curves approach is that constructions with similar structural properties are expected to show same type of seismic performance

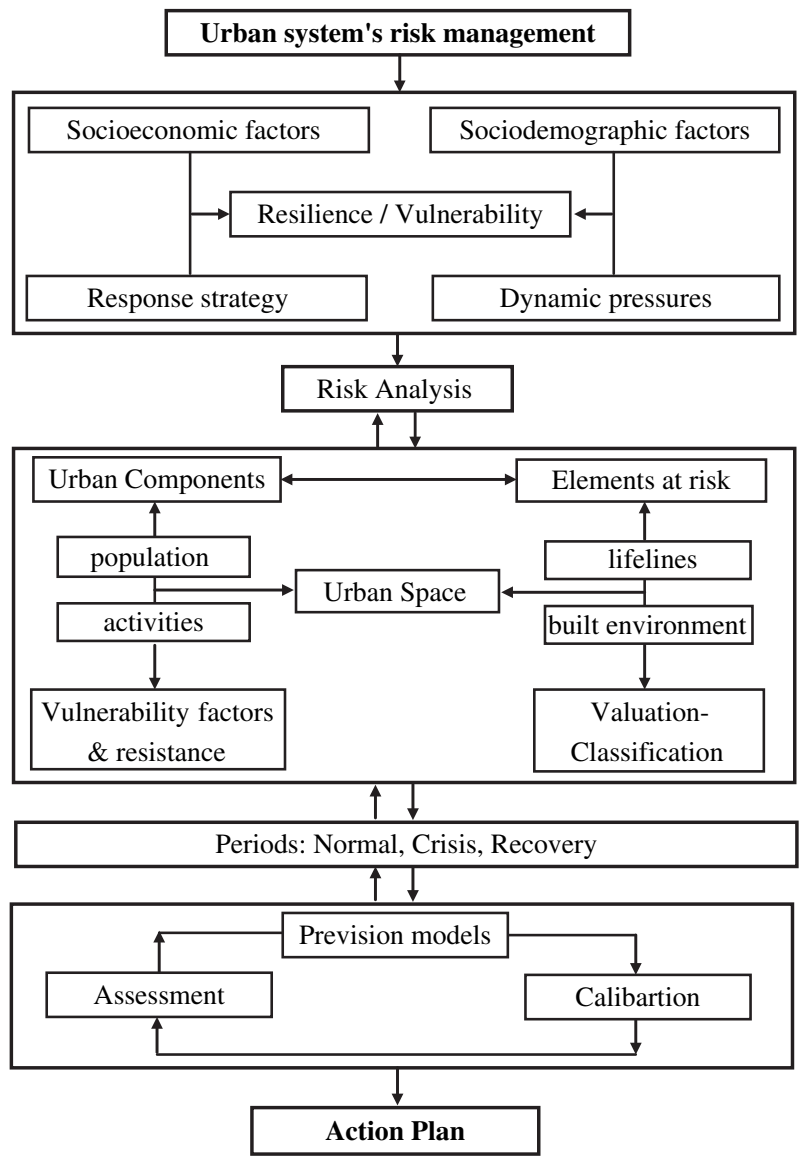

Figure 1: General layout of the urban system exposure analysis. 
under a given level of seismic loading. The fragility curves describe the probability of a structure to be in or exceed different damage states (i.e. minor, moderate, extensive and complete) for a given level of ground shaking or failure. They are usually modeled as two parameter cumulative probability density functions, characterized by a median value of ground shaking or failure and an associated dispersion factor (lognormal standard deviation) for each damage state.

HAZUS methodology [14] is an advanced multi-risk approach that has been developed in USA and incorporated in GIS software based on fragility curves that are provided for all lifeline components. Werner et al. [15] proposed a modular methodology for the seismic risk assessment of a highway network, including direct, functional and economical losses. The performance of the transportation system itself is assessed using the damage probability of each component when an earthquake is postulated $[16,17]$. The majority of the existing methods do not take into account the potential of road closure due to the collapse of adjacent buildings, as they are focusing in the assessment of direct damages of bridges and roads. However, the main threat for road network in urban areas with high building density is the collapse of buildings that can partially or fully block the adjacent streets and consequently the rescue and restoration activities could be prevented. In the present paper, a simplified approach is proposed for the definition of road blockade due to building debris, while an application is made for a central area in Thessaloniki city for a certain seismic scenario.

The extension of debris mainly depends on the height of buildings, the shape of collapse and the structural urban formation system (continuous, free, mixed, etc). Based on observations from previous earthquakes the following collapse mechanisms can be defined [18]:

- Inclined layers, consisting of 'inclined plane' 'multi layer' and 'outspread multi layer' collapse;

- Overturn collapse, mainly related with ground failure;

- Pancake collapses, including one or several storeys collapse in a uniform way;

- Debris heaps, resulting from the failure of all structural elements.

The outspread multi layer and the debris heaps are deemed to be the most critical for road closure in case of Greece.

The development of an analytical approach for the definition of street closure due to collapsed or heavily damaged buildings is a complex task as it is a multidimensional and rather chaotic problem, with many uncertainties. Moreover, the lack of documented data from past earthquakes, concerning the location and characteristics of road closures in urban areas, can't support any integrated 'scientific' approach. Few generic works have been performed on this topic mostly based on limited observed damage data and engineering judgment [19]. Due to this situation, a simple correlation between the building's height (i.e. number of storeys) and the width of the induced debris is proposed, in order to estimate the impact of collapsed buildings to the functionality of roads.

In order to establish a correlation between the initial height $(H)$ of the building and the width of induced debris $\left(W_{d}\right)$ simple collapse shapes are developed, with two variables: the ratio $\left(k_{v}\right)$ between the volume of the collapsed structure $\left(V^{*}\right)$ and the original one $\left(V_{o}\right)$ and the angle of the collapse $(f)$. In Fig. 2 is illustrated the scheme that is used in the present study, which mainly corresponds to buildings that are in contact with other buildings in two opposite sides, a case that dominates in the central Thessaloniki. The failure could occur in one direction, at the façade to the road, at the back side or both. In this study one direction failure is assumed. The visual inspection (i.e. photographs) of totally collapsed buildings from past earthquakes shows that these kinds of schemas could be representative for a wide range of structures, especially in Greece. The relationship for the estimation of the debris width $\left(W_{d}\right)$ is produced from the equation between the reduced volume (a ratio of the intact building) and the geometrical volume of the collapsed building $\left(V^{*}=k_{v} \cdot V_{o}\right)$. Based on the debris width it is possible to estimate the functionality of the road as is illustrated in Fig. 3. 


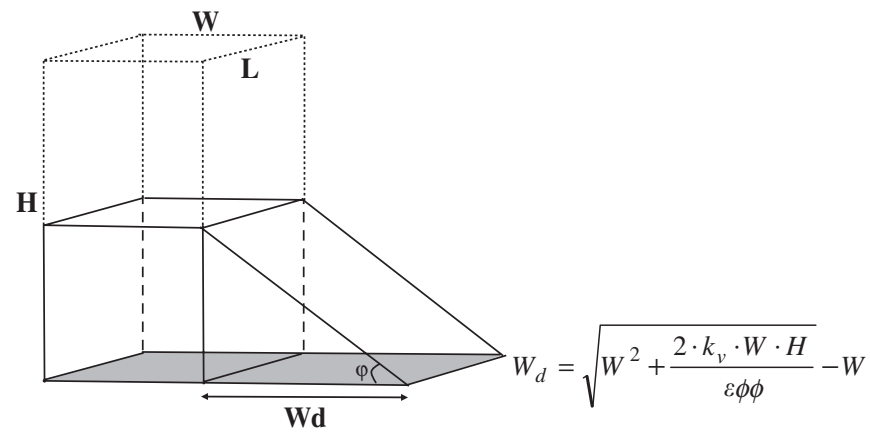

Figure 2: Definition of the induced debris width.

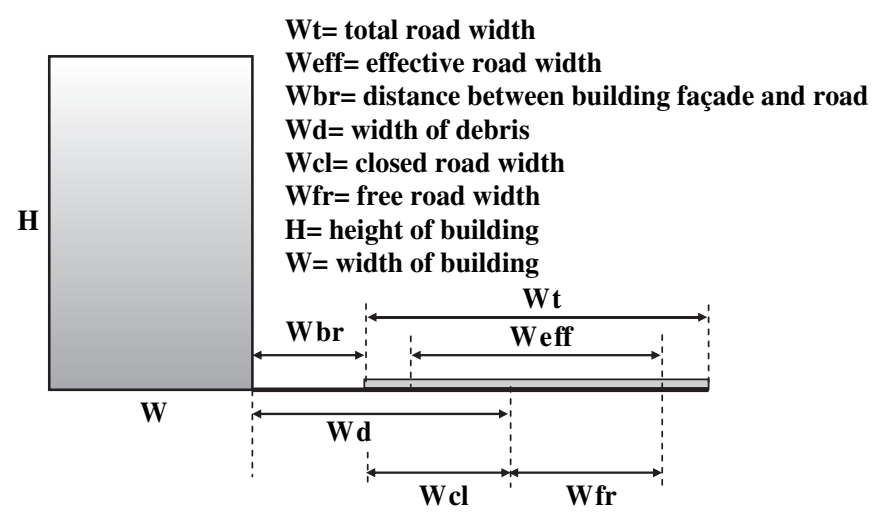

Figure 3: Definition of closed road width.

The risk analysis of buildings is performed using appropriate fragility curves, which give the probability for collapse of each building type for a certain seismic level. It is assumed that the collapse probability is equal to the occurrence probability of the corresponding debris width and the corresponding road closure. However, the collapse is not always complete or has not a shape that can produce road blockades. The experience of past earthquakes in Greece reveals that a percentage of collapses ranging between 10 and $20 \%$ can have such form and amount of debris that can result to road closure. This percentage corresponds to the one direction failure of the building towards the road that is crucial for the risk analysis of the road network. The building characteristics in relation with damage states, including collapse, have been taken into consideration at the estimation of the corresponding fragility curves.

\section{RISK MANAGEMENT AND URBAN PLANNING FRAMEWORK FOR THE CITY OF THESSALONIKI}

The city of Thessaloniki is located on the Axios-Vardar seismogenic zone, which is adjacent to the Servomacedonian massif, one of the most seismotectonically active regions in Europe [20]. The broader area has been stricken by destructive earthquakes during the last century, while the latest major event occurred in June 1978 with an epicenter located at a distance of about $25 \mathrm{~km} \mathrm{NE}$ of the city and a magnitude of $\mathrm{M}=6.5$. The earthquake caused a nine-storey $\mathrm{R} / \mathrm{C}$ building collapse, few partial collapses and extended damage to buildings, with 48 deaths and 220 injuries in total. 
Thessaloniki is a linear city extending along the seaside and consequently the road system follows this geomorphology being parallel and perpendicular to the sea. A basic characteristic of the organization of city planning is the high population density as a result of high building ratio and, thus, the high residential density. We are dealing with values that exceed the accepted standards set by city planning legislation both in Greece and the European Union. Their negative range becomes particularly evident when correlated with the very few free spaces left in the urban environment and the inefficiency of infrastructure (roads network and city transport). In view of this, the highdensity section of the Urban Region of Thessaloniki, consisting of the central borough and the newer north-western boroughs, is characterized as an area of high risk.

In general, experience has shown that the most problematic parameters in shielding the city from seismic risk are the following:

- Building ageing, especially at the heart of the urban tissue of the city, with construction dating back to the 1950 s.

- Stagnation as regards construction quality, the absence of systematic supervision and the lack of a private-sector construction register.

- Absence of anti-seismic conscience and of a spirit of co-operation between architect, engineer, contractor and owner. The shortsighted attitude towards the economic parameter, the prevalence of financial interest over all aspects of building construction and supervision.

- Potentially hazardous urban planning (high building density, lack of free spaces, etc.)

- Deficiencies in administrative infrastructures regarding the prevention and management of seismic risk.

- Insufficient road system, especially in the center, where the densely built up area creates a complex network, with narrow streets and inadequate parking areas.

- Inappropriate design of pedestrian roads.

- Unplanned extensions of city plans.

- Building on an arbitrary basis.

- Insufficiency of special architectural planning regulations concerning important buildings of the city (historical buildings, monuments, etc.), critical constructions, and buildings of strategic significance and infrastructures.

\subsection{Value analysis of urban system}

The present application is performed in a part of the 'intra miros' historical center of the city, an area with high building densities and a variety of functions. The urban vulnerability analysis is followed by the proposal of an urban planning framework in line with seismic risk management. On a first level, the aim is the identification of crisis data as regards the urban environment, with a view to preventing potential adverse effects, in other words, the aim is to lay out preventive planning. On a second level, the aim is the creation of appropriate conditions for the reinstatement of the city and for its restoration to normal conditions of operation.

In that way, according to the general decision-making framework, three periods of functioning are defined:

- The normal period: This is the reference point of planning and it represents the period of normal functioning of the city before the earthquake. The analysis of the system's operations during this phase is essential in identifying its vulnerable elements as well as its developmental potential, while also contributing to an understanding of the possible crisis circumstances. The aim is to put forward all growth processes of the city - planning, economic, social, cultural - within a preventive 
planning and negotiation framework as regards seismic risk, one in which all conditions necessary for the protection and shielding of the city are assured.

- The crisis period: The onset of this phase is signaled by the catastrophic event itself, while its duration is a function of the earthquake magnitude, the level of losses and the city's elements at risk. It usually lasts from a few days to some weeks, at the most. It is a particularly critical period, which requires the mobilization of specialized emergency services of the city. Of utmost importance is the prompt administration of first aid to the earthquake casualties and the immediate response to the vital needs of all victims.

- The recovery period: This phase can also be termed a return to autonomy phase. The urban and spatial planning proposals and decisions related to this phase, give rise to a novel approach to urban space, while efforts made are focused on the scheduling of the necessary actions for the city to regain a minimum required number of basic functioning conditions. The restoration of the city's activities depends on the relative delay of the recovery of basic functions (energy networks, transportation networks, etc.) All these are directly related to the preparation that has taken place in the city during the phase of normal growth.

Two planning levels were specified for the city of Thessaloniki, the one that concerns the vulnerability parameters of the city - hazard identification and specification of crisis consequences - and the other which concerns risk management and the methods of handling the events and their consequences. This is an alternative form of sustainable development of the city, in which the concept of 'sustainability' refers to particular interventions in the organization of the housing environment, in such a way that its behavior in the event of an earthquake will respond to the social needs. The application of the urban value approach was performed in four subsequent steps, [1]:

Step 1: First, the elements at risk are divided into 'areas', 'groups', 'point' and 'linear' elements. In order to define the areas of risk, the overall area is divided in zones according to land use (residential and trade zones). The groups at risk refer to a grouping of urban elements such as the building stock. The point elements at risk concern cultural, monumental, educational, administrative, medical care, and emergency buildings, hotels, city symbols, etc. The linear elements comprise lifeline components such as roads and pipes.

Step 2: The analysis of each element is based on the following urban components: population, activity, urban space, functions and identity of the city. Each component is characterized by an urban indicator such as residents, workers, housing, business-trade, building, social, decision-making and radiance. The basic urban indicators used are the population density, functions density, housing density, radiance, historical significance, land values, etc. In the same way, the economic indicator can be the purchasing price and employment rate, for the human factor, the number of people, for the functional indicator, the social usefulness, for the environmental indicator the natural resources, for the strategic indicator, effectiveness and immediacy of response to the natural disaster phenomenon, for the decision-making indicator the force and potency of the decision and for the symbolic indicator, radiance and 'image' value.

Step 3: In case of Thessaloniki, the measuring units of each indicator are identified, based on appropriate quantitative or qualitative criteria. The main measuring units for the residential, trade and building stock areas are the population density (inhabitants/ha), the trade density (workers/ha), the housing area density $\left(\mathrm{m}^{2} / \mathrm{ha}\right)$, the trade area density (trade $\mathrm{m}^{2} / \mathrm{ha}$ ), the influence scale, the structure coefficient, the market price and the building area density (built $\mathrm{m}^{2} / \mathrm{ha}$ ). Few examples of measuring units for the point elements are the concentration of visitors for public buildings, the number of beds for hospitals, the intervention capability for fire stations or the symbolic weight for monuments. The measuring units are transcribed to a relative value scale depending on available data. The threshold values are defined based on a statistical analysis in case of quantitative data or a qualitative analysis 
Table 1: Indicators per period for the residential, trade and building stock elements.

\begin{tabular}{|c|c|c|c|c|c|c|}
\hline Element & Component & Indicator & Measuring Units & Normal & Crisis & Recovery \\
\hline \multirow{3}{*}{$\begin{array}{l}\text { Residential } \\
\text { zone }\end{array}$} & Population & Residents & Inhabitants/ha & $\checkmark$ & $\checkmark$ & - \\
\hline & Functions & Housing & $\begin{array}{l}\text { Housing area } \\
\text { density }\left(\mathrm{m}^{2} / \mathrm{ha}\right)\end{array}$ & $\checkmark$ & - & $\checkmark$ \\
\hline & Identity & Radiance & Influence scale & $\checkmark$ & - & $\checkmark$ \\
\hline \multirow{3}{*}{ Trade zone } & Population & Workers & Workers/ha & $\checkmark$ & $\checkmark$ & - \\
\hline & Activities & Business-trade & $\begin{array}{l}\text { Trade area density } \\
\left(\mathrm{m}^{2} / \mathrm{ha}\right)\end{array}$ & $\checkmark$ & - & $\checkmark$ \\
\hline & Identity & Radiance & Influence scale & $\checkmark$ & - & $\checkmark$ \\
\hline \multirow[t]{4}{*}{ Building stock } & Urban space & Building & $\begin{array}{l}\text { Structure } \\
\text { coefficient }\end{array}$ & $\checkmark$ & - & - \\
\hline & & & Market price & $\checkmark$ & & $\checkmark$ \\
\hline & Functions & All & $\begin{array}{l}\text { Built area density } \\
\left(\mathrm{m}^{2} / \mathrm{ha}\right)\end{array}$ & $\checkmark$ & - & $\checkmark$ \\
\hline & Identity & Radiance & Influence scale & $\checkmark$ & - & $\checkmark$ \\
\hline
\end{tabular}

otherwise. As an example the relative values for the population density in Thessaloniki are assigned as 1 , for $>1500$ inhabitants/ha; 0.75 for $>1000$ inhabitants/ha; 0.50 for $>500$ inhabitants/ha; 0.2 for $<500$ inhabitants/ha. The value scale for the symbolic weight is defined as 1.0 for major, external recognition; 0.5 for important, local recognition; 0.3 for low, inner recognition.

Step 4: According to the considered function period, the relevant indicators are selected for each element at risk. The indicators per period for the residential, trade and building stock elements are shown in Table 1. The global value is calculated for each element and for each period, while individual graphs with the distribution of the global value are produced. The discontinuities within the distribution are utilized in order to define the threshold values for the assessment of the main, important and secondary issues for each period (Fig. 4).

In Figs 5, 6 and 7 the results for the trade and residential zones in normal and crisis periods are shown. The majority of residential zone is characterized by main issues as the study blocks are described by high population and building's densities. This phenomenon is more intensive during the normal period where all the urban parameters are considered, than in crisis period where only the population is critical (Table 1). On the other hand, the trade zone is characterized by a minority of main issues that are concentrated in the CBD of the town.

A further series of secondary potential vulnerability indicators is also identified, with respect to the various urban planning parameters [7], such as:

Urban space and the environment (fire spread parameters - accessibility, road width - , earthquake debris volume and time required for their disposal/ removal), population (sociocultural characteristics), occupation (nature of activities, capacity, dependence on external factors), central functions (influence from external factors, concentration, possibility of replacement), urban administration parameters (knowledge, perception and recognition of the gravity of risk and of its consequences), identity and external image of the city (provision of information regarding the risk, media sensitivity). Finally, the evaluation of social and functional vulnerability is also significant, as is the potential of social conflicts within the urban system, due to the interdependence of central functions and activities, decision-making centers, conflicts of interest and the reaction of the public. 


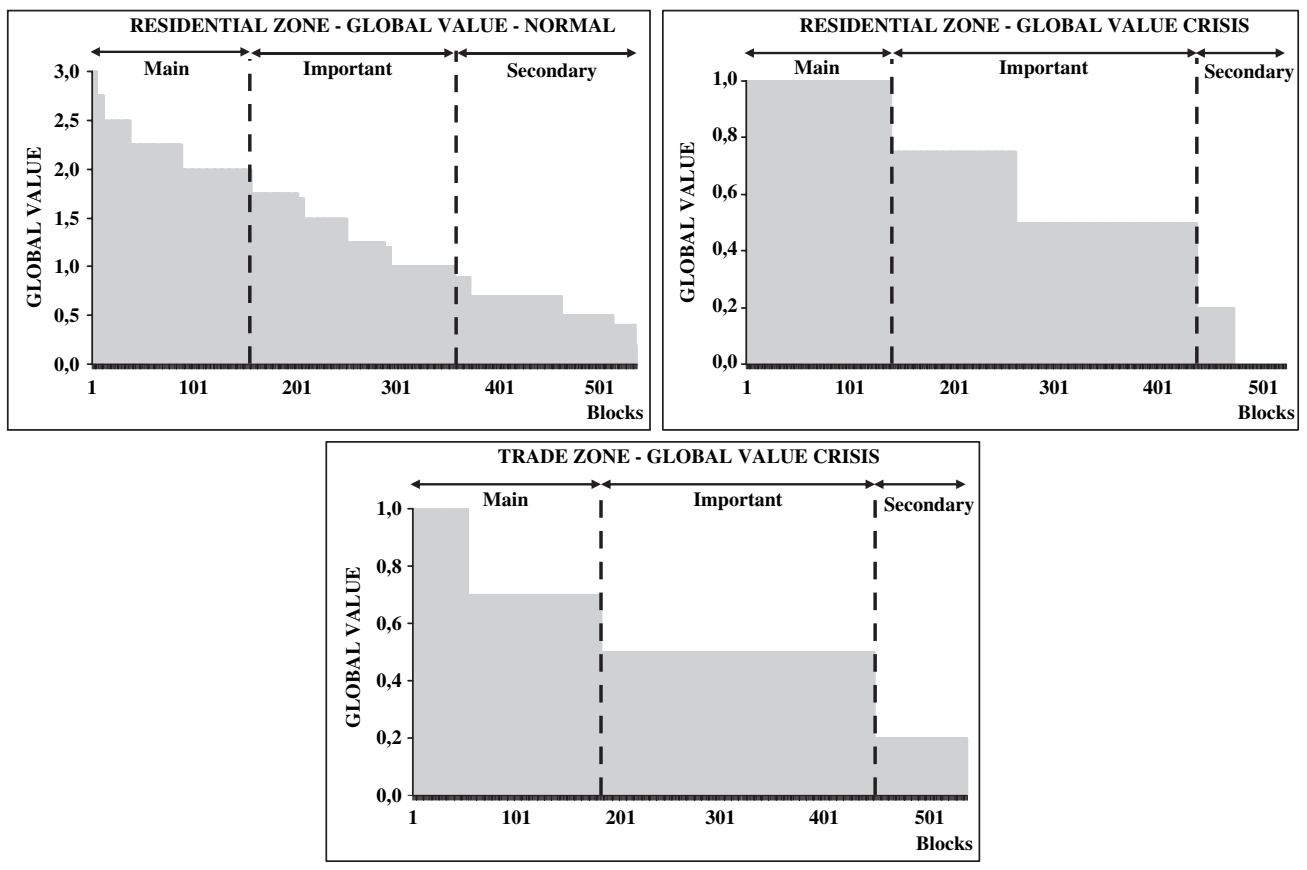

Figure 4: Definition of main, important and secondary blocks for residential and trade zone in normal and crisis period based on the distribution of the global values.

The results of this study combined with the outcome of the vulnerability assessment of the exposed elements at risk such as current buildings, monumental and historical buildings, lifelines and essential structures and their subcomponents, will contribute to the development of an efficient mitigation strategy and a well-organized emergency planning of the city. Therefore, based on the classification of the importance and the role of the above elements in normal, crisis and recovery periods and the expected physical damages, it could be possible to define prioritization policies for appropriate pre-earthquake retrofitting or restoration actions. In that way, focus will be placed on limiting the necessary recovery period to the least possible extent, in order to provide the related city activities with the optimum feasible operation level. The role of the local actors (city planners, risk managers, lifeline owners and others) is essential in order to validate the results and to develop earthquake crisis management strategies.

\subsection{Road network}

The inventory of the road network in Thessaloniki is incorporated in GIS environment and includes information about the total and effective road width, the classification of the road, the number of lanes and the average distance between buildings' façade and road. Based on these values and the induced debris width, the closed and free road width is calculated for each road segment according to Fig. 3. The debris width is defined according to the model that is shown in Fig. 2, for $W=15 \mathrm{~m}$, $k_{v}=V^{*} / V_{o}=0.5$ and $f=45^{\circ}$ assuming an average building height in each block, as there are not significant hypsometric differences in this area. This pilot study is performed for the main streets in the study area, which are characterized as critical in case of emergency, while the local streets are 


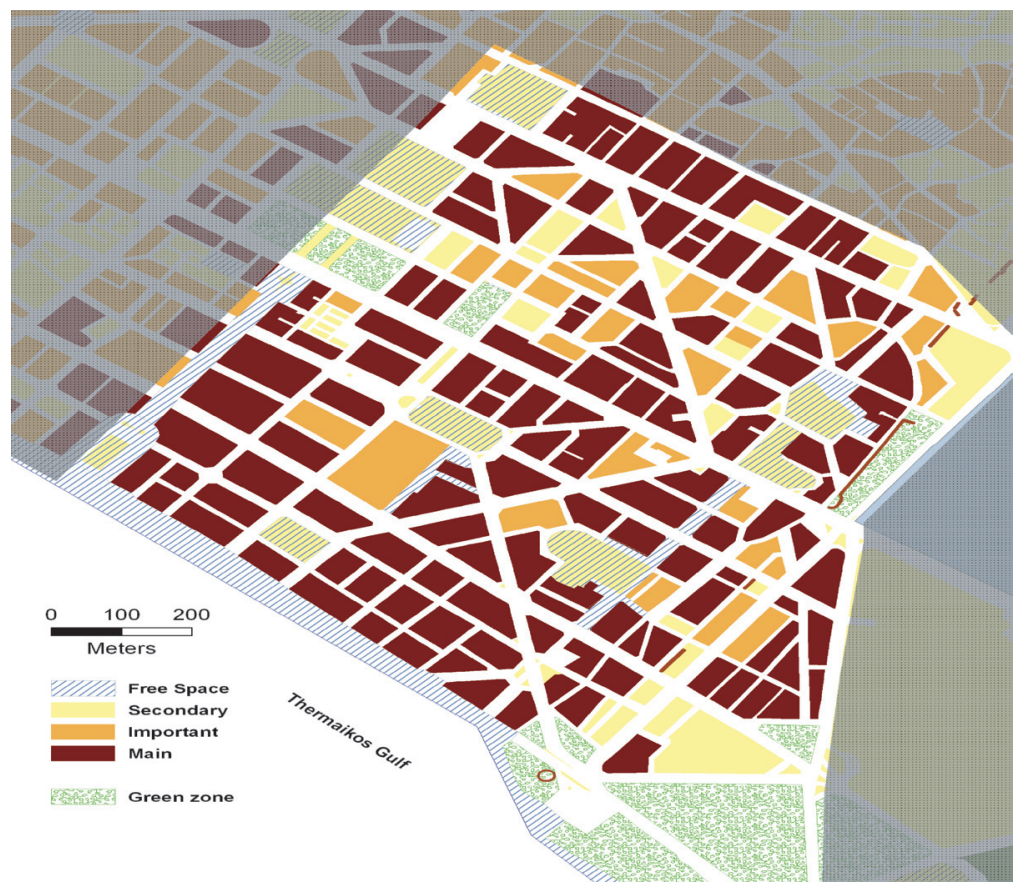

Figure 5: Estimation of urban vulnerability of residential zone for the normal period.

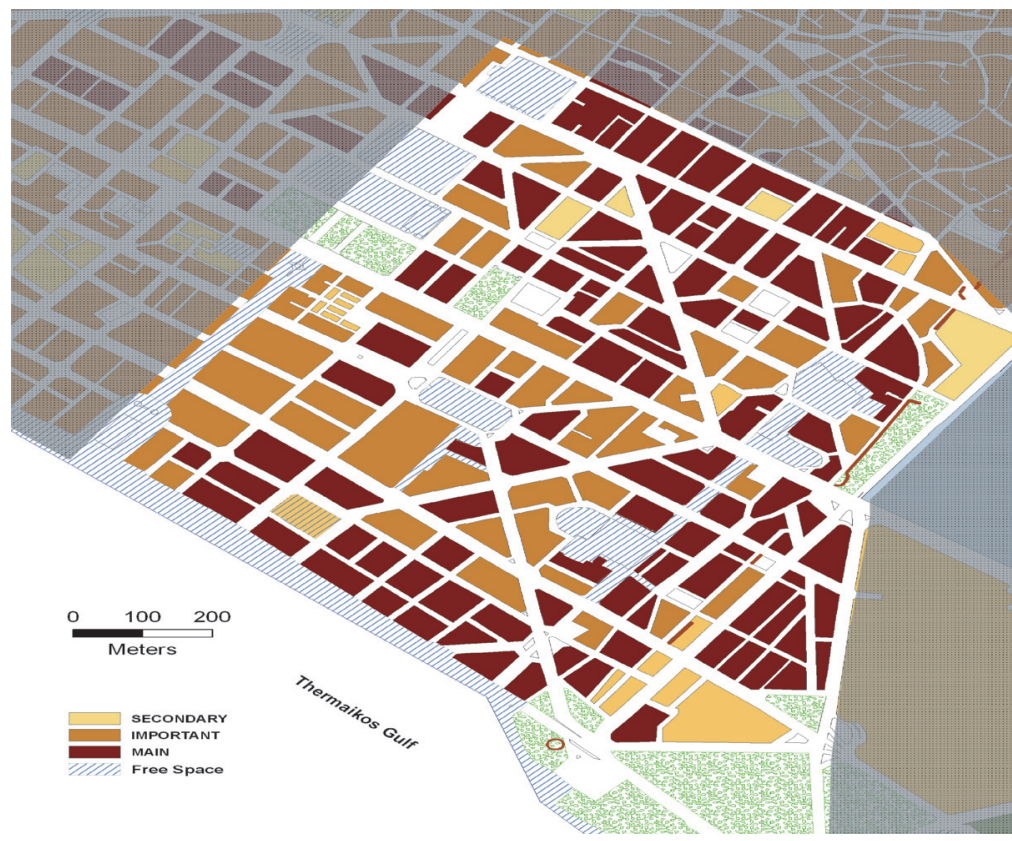

Figure 6: Estimation of urban vulnerability of residential zone for the crisis period. 


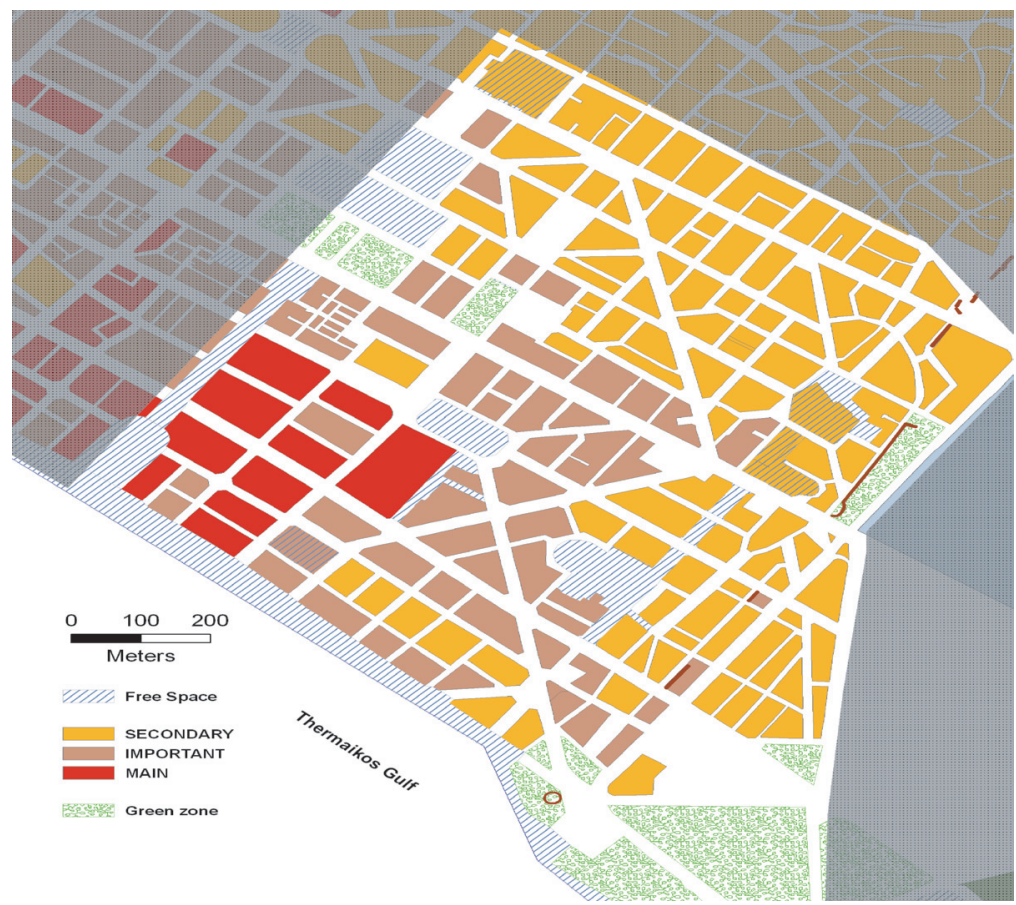

Figure 7: Estimation of urban vulnerability of trade zone for the crisis period.

not considered. It is remarkable that in many cases the effective width of the roads in this area is much less than the actual width due to the parked cars (usually illegally). The road lines are divided in segments which are defined from the intersections of the road axis.

The vulnerability assessment of buildings is performed for the seismic hazard scenario that is derived from the microzonalization study of Thessaloniki. The latter is made for an earthquake scenario with $10 \%$ probability of incidence in 50 years, based on the seismic hazard analysis of the area, while it includes a great number of site-specific ground response analyses [21]. The buildings of each block are classified according to the height (i.e. number of storeys), structural type, material and seismic code level. The damage level is estimated based on appropriate fragility models which have been developed for the building types commonly present in Thessaloniki as a function of the peak ground acceleration $[22,23]$. It is noted that the most vulnerable building type that appears to have by far the higher collapse probability, is the reinforced concrete buildings constructed by frames (i.e. without walls), medium height (i.e. 4-7 storeys), designed according to old codes (1959-1984 period).

As the exact location of the buildings within the block is not available it is assumed that they could be found at all sides of the block and thus the collapsed probabilities are distributed based on the length of each side. For each road segment a total closure probability is derived from the discrete collapse probabilities of the block's façade along the two sides of the road. The final probability is estimated considering the number of buildings within the block and a factor which defines the percentage of collapses with a shape that is critical for road closure that is taken equal to 0.2. In Fig. 8 is presented a map with the results of the study. The roads are categorized in 4 classes according 


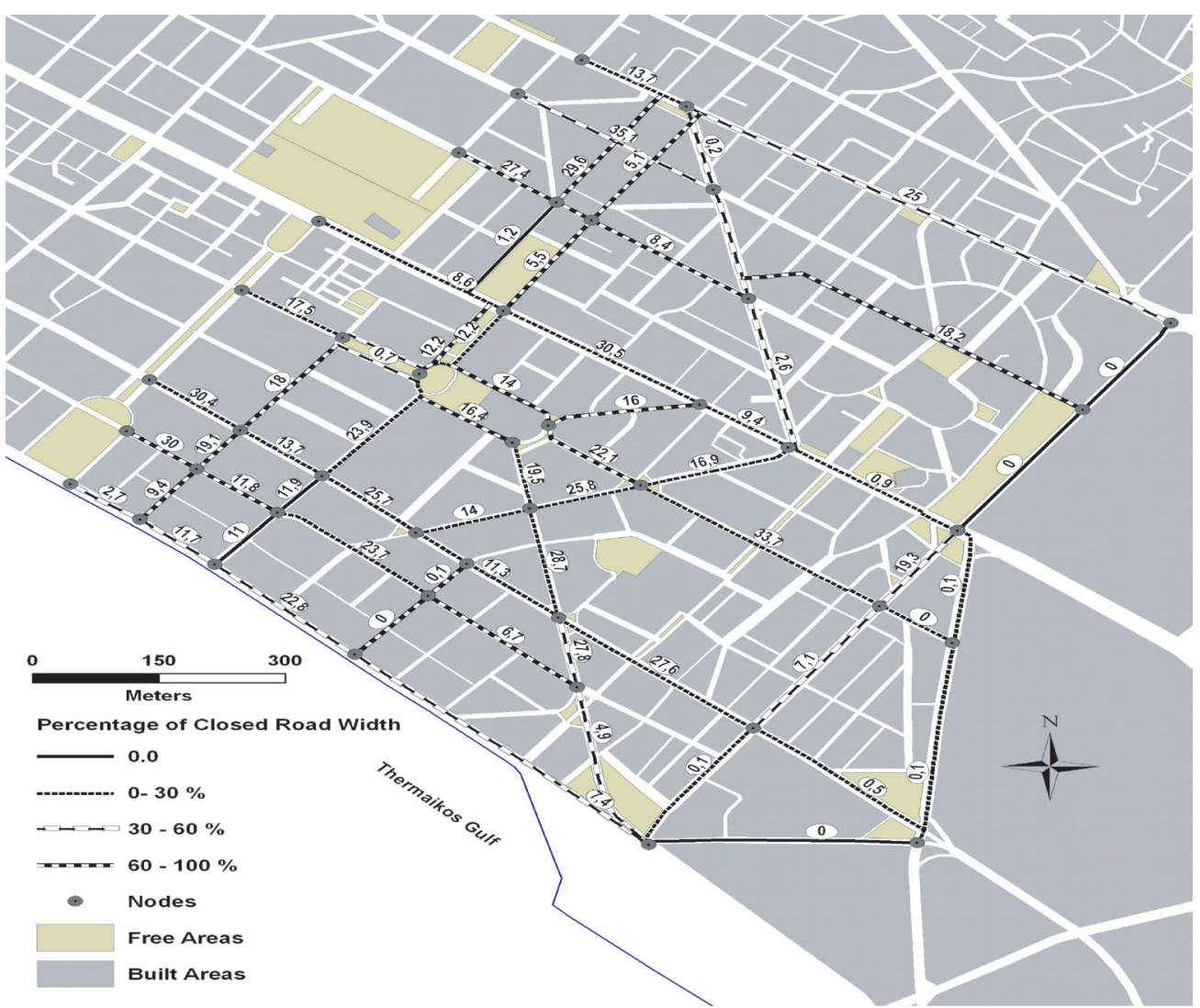

Figure 8: Estimation of road closure probabilities in the study area.

to the reduction of road width (\%) due to the adjacent building debris. Above each road segment is shown the probability that has been calculated following the aforementioned procedure.

The reduction of the road width ranges from 0 to $100 \%$ depending on the distance from the buildings, the width of the road and the induced debris width. The probabilities for the corresponding road closures range from 0 to $40 \%$ depending on the concentration of the most vulnerable building type, the length of the road segment and the discrete collapse probabilities.

\section{CONCLUSIONS}

In the present paper a methodology for the seismic risk management in urban areas is described. The urban vulnerability assessment of elements at risk is performed through a value analysis approach based on appropriate indicators such as population, residential and trade densities, radiance and others, while a pilot application is made for Thessaloniki. The vulnerability of road network is also examined based on the interaction between collapse patterns of adjacent buildings and network functionality. Due to the complexity of the problem and the lack of data from previous earthquakes a simple model is introduced in order to correlate the building's height with the induced debris width. The collapse probabilities of buildings are combined with the road closure in order to perform a preliminary application for the roadway network of the central Thessaloniki. The synthesis of the road network risk study due to building collapses and the urban vulnerability analysis could provide a valuable 
tool for an effective seismic risk management as the priorities for the pre-earthquake and emergency actions could be defined. The main results of the study are summarized to the following:

The basic characteristics of the study area, as well as of the entire agglomeration, are the high population and function densities, something which, combined with the high seismicity of the Greek territory, renders the city particularly vulnerable in the event of an earthquake. With regard to structural vulnerability the fragility analysis for the specific scenario shows that buildings have high damage probability. This is due to the fact that the majority of them have been built according to older seismic regulations, before 1984, but primarily even before 1970, and have limited static adequacy, contrary to the city's expansions, which have been structured according to the most recent seismic regulations and are, therefore, better shielded. As far as urban vulnerability is concerned, residential zones and trade zones are in the majority characterized as main and important, according to the respective global values. Combined with the above, the traffic congestion and the uncontrolled parking are likely to constitute a serious obstacle regarding the population mobility as well as the free movement of emergency services, ambulances, etc., in the case of an earthquake.

On a planning level, the following measures are deemed essential: the revision of structure coefficients, the more rational spatial planning of central functions, the creation of open spaces and the organization and optimal use of private open spaces between buildings, the specification of escape paths to the areas above, the implementation and enforcement of parking control policy, and, finally, the systematic inspection of buildings and their structural strength in seismic loading.

\section{REFERENCES}

[1] RISK-UE, 'An advanced approach to earthquake risk scenarios with applications to different European towns', Contract: EVK4-CT-2000-00014. Final report of WP14: Synthesis of the Application to Thessaloniki City, 2004.

[2] Gleick, J., Chaos, The Making of a New Science, Penguin, USA, 1988.

[3] McEnture, D.A., Fuller, C., Johnston, C.W. \& Weber, R., A comparison of disaster paradigms: the search for a holistic policy guide. Public Administration Review, 62(3), pp. 267-281, 2002.

[4] Lewis, J., Development in disaster-prone places: studies of vulnerability, Intermediate Technology, Prentice Hall: Boston, 1999.

[5] Weichselgartner, J., Changer au rythme des changements: Les défis s'adressant à la gestion des risques naturels. RisquesNaturels et Aménagement en Europe, ed. Y. Veyret, pp. 212-221, Armand Colin: Paris, 2004.

[6] Weichselgartner, J. \& Bertens, J., Natural disaster reduction in Europe: a Don Quixotic project in the face of a changing world. Risk Analysis III, ed. C.A Brebbia, WIT Press: Southampton, pp. 233-242, 2002.

[7] Anastassiadis, A., Urban planning and risk management, Proc. of the 8th International Conference on Environmental Science and Technology, pp. 16-23, Lemnos, 2003.

[8] Anastassiadis, A., Anastassiadis, An. \& Pitilakis, K., Reconstruction of declining and destroyed areas of Europe, Pilot Research into urban planning data in correlation with the ground seismic response in the business-historical centre of Thessaloniki, pp. 225-241, 2002.

[9] Pitilakis, K., Alexoudi, A., Argyroudis, S., Monge, O. \& Martin, C., Vulnerability assessment of lifelines (Chapter 9), Assessing and Managing Earthquake Risk. Geo-Scientific and Engineering Knowledge for Earthquake Risk Mitigation: Developments, Tools and Techniques, eds. C.S. Oliveira, A. Roca \& X. Goula, Springer, 2006.

[10] Shinozuka, M., M.Q. Feng, H.-K. Kim, T. Uzawa, \& Ueda T., Statistical analysis of fragility curves. Technical Report, MCEER-03-0002, State University of New York, Buffalo, 2003. 
[11] Basoz, N. \& Kiremidjian, A.S., Evaluation of bridge damage data from the Loma Prieta and Northridge, California earthquake. Technical Report, MCEER-98-0004, Buffalo: State University of New York, 1998.

[12] Mander, J. \& Basoz, N., Seismic fragility curve theory for highway bridges. Proc. of the 5th US Conf. on Lifeline Earthquake Engineering, eds. M. Elliot \& P. McDonough, TCLEE/ASCE, Monograph No.16, August 12-14, Seattle, Washington, 1999.

[13] ATC-25. Seismic vulnerability and impact of disruption of lifelines in the conterminous United States. Applied Technology Council (ATC), Redwood City, CA, 1991.

[14] NIBS, National Institute of Building Science. Earthquake loss estimation methodology. HAZUS. Technical Manuals. Federal Emergency Management Agency (FEMA), Washington, Vol. 1, 2, 3, 1997, 1999 \& 2002.

[15] Werner, S.D., Taylor, C.E., Moore, J.E., Walton, J.S. \& Cho, S., A risk-based methodology for assessing the seismic performance of highway systems. Technical Report MCEER-00-0014, Buffalo: State University of New York, 2000.

[16] Chang, S.E. \& Nojima, N., Measuring post-disaster transportation system performance: The 1995 Kobe earthquake in comparative perspective. Transportation Research, A35, pp. 475-494, 2001.

[17] Nojima, N. \& Sugito, M., Simulation and evaluation of post-earthquake functional performance of transportation network. Proc. of the 12th World Conf. on Earthquake Engineering, Auckland, NZ, Paper No. 1927, 2000.

[18] Schweier, C. and Markus, M., Classification of collapsed buildings for fast damage and loss assessment. Bulletin of Earthquake Engineering, 4(2), pp. 177-192, 2006.

[19] Argyroudis, S., Pitilakis, K. \& Anastasiadis, A., Roadway network seismic risk analysis in urban areas: The case of Thessaloniki-Greece. Proc. of the International Symposium of GEOLINE, eds. M. Arnould \& P. Ledru, BRGM editions (CDROM), Lyon, 23-25 May, 2005.

[20] Papazachos, B.C., Mountrakis, D., Psilovikos, A. \& Leventakis, G., Surface fault traces and fault plane solutions of the May-June 1978. Major shocks in the Thessaloniki area, Greece. Technophysics, 53, pp. 171-183, 1979.

[21] Pitilakis, K., Alexoudi, M., Argyroudis, S. \& Anastasiadis, A. Seismic risk scenarios for an efficient risk management: The case of Thessaloniki (Greece).Advances in Earthquake Engineering for Urban Risk Reduction, eds. S.T. Wasti \& G. Ozcebe, Springer, pp. 229-244, 2006.

[22] Kappos, A.J., Panagiotopoulos, C., \& Panagopoulos, G., Derivation of fragility curves using inelastic time-history analysis and damage statistics, Proc. of the ICCES'04, Madeira, Portugal, July, (CDROM), 2004.

[23] Penelis, Gr.G., Kappos, A.J., Stylianidis, K.C. \& Panagiotopoulos, C., 2nd level analysis and vulnerability assessment of URM buildings, Proc. of the International Conf. on Earthquake Loss Estimation and Risk Reduction, October 24-26, Bucharest, Romania, 2002. 